\title{
Reciprocidade e acolhimento na educação de jovens e adultos: ações intencionais na relação com o saber
}

\section{Reciprocity and shelter in the youth and adult schooling: the intentional actions in the knowledge relationship}

\author{
Maria Hermínia Lage Fernandes Laffin *
}

\begin{abstract}
RESUMO
Apresentando resultados da pesquisa de doutorado, o artigo destaca particularidades dos processos educativos de jovens e adultos, situando a busca dos sujeitos de uma relação com o saber, as diferentes mediações da organização do trabalho pedagógico na Educação de Jovens e Adultos e a questão da reciprocidade e acolhimento como ações intencionais no processo ensinoaprendizagem. Ao concluir o estudo, constata-se uma docência na qual o sujeito se torna professor/a no seu fazer e no seu caminhar, que vem contribuindo para a construção de um estatuto próprio de EJA, para a produção e acúmulo de saberes teórico-metodológicos, potencializando um campo pedagógico e de pesquisa.

Palavras-chave: docência na educação de jovens e adultos; particularidades do processo educativo e acolhimento para o ato do conhecimento.
\end{abstract}

\begin{abstract}
Presenting results of the doctoring research, the article discusses the special aspects of educational processes of Youth and Adult Schooling searching of the people related with knowledge, the different mediations of organization about pedagogical work and the question of the reciprocity and shelter as
\end{abstract}

* Professora da Universidade Federal de Santa Catarina. Doutora em Educação/UFSC/ SC. E-mail: herminia@ced.ufsc.br. 
intentional actions in the process teach-learning. At the end of the work, the teaching profession is acknowledged as an endless process, for the individual becomes a teacher as he lives and acts thus contributing to the constitution of a peculiar form of youth and adult education, to the production and accumulation of theoretical and methodological knowledge which constitutes a field of research in itself.

Key-words: the teaching profession in the youth and adult schooling; peculiar form of educative process and shelter for the act of the knowledge.

\section{Introdução}

Considerar as particularidades que se configuram no exercício da docência de Educação de Jovens e Adultos (EJA) constituiu questão central de pesquisa de doutorado, "A constituição da docência entre professores da escolarização inicial de Jovens e Adultos", tomando como referência vinte e três professoras da Rede Municipal de São José/SC, na qual foram examinados modos de lidar não só com os sujeitos, mas também com as práticas pedagógicas de EJA. O estudo desta temática se justifica, uma vez que a escola representa o lugar socialmente organizado com a função de trabalhar intencionalmente no processo de desenvolvimento e aprendizagem da cultura humana. Sabemos que esse desenvolvimento não se dá apenas no âmbito da escolarização, mas também em outras práticas e atividades culturais.

Destaca-se nos dados da pesquisa que uma primeira necessidade/interesse dos alunos ao procurarem a EJA é percebida pelos docentes como uma necessidade ligada ao conhecimento - ler e escrever - não necessariamente numa situação utilitarista, havendo uma preocupação com o conhecimento e saberes valorizados socialmente.

Esses indivíduos vivenciam cotidianamente desigualdades sociais e raciais perante o mundo, no qual se inclui a escola, que também é desigual, o que não pode traduzir-se num determinismo causal de condições de sucesso na escola, e, no caso da EJA, não pode significar uma fragilização e aligeiramento da escolarização na relação com o saber científico, com o conhecimento.

Então, indica-se no processo da EJA que as propostas, ao lidarem com o conhecimento, não sejam utilitaristas, imediatistas, ou seja, selecio- 
nar e trabalhar com conteúdos que partem e ficam especificamente somente na realidade próxima dos seus alunos, mas que possam avançar no sentido de aprender os conhecimentos ditos do mundo letrado e que podem ajudar o aluno a fazer, como diz Paulo Freire, uma leitura mais ampliada de mundo. Conforme afirmam os docentes investigados:

É preciso considerar que os alunos da EJA já têm uma história que já viveram. $\mathrm{O}$ aluno da EJA traz consigo uma grande bagagem de vida. Pedro -35 anos.

O que diferencia é que o adulto já vem com uma bagagem variada, nosso trabalho é ajudá-lo a desenvolver suas potencialidades. Isabel -59 anos

Visualizando essa história de vida é que se experiencia o desafio de analisar, no processo de escolarização de jovens e adultos, a realidade da escola e do contexto social, em que tanto professores como alunos vêm construindo e encontrando objetivos e significados para a aprendizagem.

Nesse sentido, o grupo de docentes salienta a importância de considerar a história de vida e a intencionalidade dos sujeitos ao procurarem a escolarização, ao pensar a organização metodológica da aula, os critérios para a seleção dos conteúdos do ensino e as atividades. Os professores apontam ainda que, ao definirem os conteúdos desenvolvidos na prática pedagógica da Educação de Jovens e Adultos, no processo de escolarização inicial procuram construir temáticas a partir da escuta dos alunos.

Percebem-se, assim, no trabalho da EJA indicações de um compromisso com a questão do conhecimento, quando os professores situam que os critérios principais para a seleção de conhecimentos, dos conteúdos escolares são

(...) as necessidades trazidas pelos alunos junto com o conhecimento científico, seus interesses, a valorização (pessoal), de acordo com os conhecimentos prévios, seu nível de conhecimento; logo, as necessidades dos mesmos, a partir das quais elencamos um tema comum para os grupos e organizamos as atividades pelos interesses dos alunos (DADOS DE PESQUISA - 2003/2005). 
Capta-se nesses dados o quanto os professores, nos seus depoimentos, valorizam a intencionalidade dos sujeitos na constituição da sua relação com o saber ao procurarem a escolarização, uma vez que vivem numa sociedade que valoriza práticas de uso da escrita e do conhecimento sistematizado. Dessa forma, o sujeito se vê inserido num contexto, para o qual Charlot (2000) afirma que isso significa

(...) ver-se submetido à obrigação de aprender. Aprender para construirse, em um triplo processo de "hominização", de singularização, de socialização. Aprender para viver com outros homens com quem o mundo é partilhado. Aprender para apropriar-se do mundo, de uma parte desse mundo, e para participar da construção de um mundo pré-existente. Aprender em uma história que é, ao mesmo tempo, profundamente minha, no que tem de única, mas que me escapa por toda a parte. Nascer, aprender, é entrar em um conjunto de relações de processos que constituem um sistema de sentido, onde se diz quem eu sou, que é o mundo, quem são os outros (CHARLOT, 2000, p. 53).

Para esse pesquisador, esta é uma condição que faz do filho do homem um sujeito, sempre em interação, partilhando o mundo com os outros. Para isso, faz-se necessário que o sujeito “(...) se aproprie do mundo e construa a si mesmo, se eduque e seja educado" (CHARLOT, 2000, p. 49).

Um conceito fundamental levantado por esse pesquisador refere-se à noção de devir do sujeito humano. Para ele, o sujeito humano não é, mas “(...) deve ser; para tal, deve ser educado por aqueles que suprem sua fraqueza inicial e deve educar-se, 'tornar-se por si mesmo"” (CHARLOT, 2000, p. 52).

O sujeito constrói sua própria história singular inscrita na história do gênero humano, e dessa forma ocupa um lugar social, no qual exerce uma atividade em que ele produz e se produz a si mesmo. Mas Charlot (2000, p. 54) alerta que essa produção só é possível pela mediação do outro e com sua ajuda. Para que esse processo se efetive, é necessário que o sujeito tenha essa intencionalidade, ou seja, que consinta e que colabore nesse processo. Para tanto, o sujeito precisa encontrar também mediações e condições objetivas no mundo que oportunizem e possibilitem esse processo educativo. 
Pensa-se uma escola de EJA em que se produzem novos saberes e heranças culturais no sentido de promover maior compreensão sobre $o$ mundo em que se vive.

\section{Diferentes mediações da organização do trabalho pedagógico na Educação de Jovens e Adultos}

Um aspecto fundamental indicado pela pesquisa refere-se ao modo como os educadores de EJA constroem alternativas para lidar com os diferentes níveis de conhecimento e de ritmos de aprendizagem no espaço da aula. Essas alternativas ficam evidentes nos depoimentos dos professores, ao situarem os modos como lidam com seus alunos jovens e adultos, como pensam a aula e como definem as atividades para a sua ação, isto é, como definem as ações específicas de atuação no âmbito da aula como professores de jovens e adultos:

- Eu organizo a aula dependendo do grupo, do número de alunos que tem na sala. Eu faço assim, tem o plano da aula programado e sempre uma aula de apoio. Maria Heloísa -38 anos

- A minha turma é sempre o mesmo número de alunos, então eu tenho sim, uma certa rotina. Faço chamada, distribuo atividades e vou vendo quem fez ou o que não fizeram em casa. Vou corrigindo a atividade, as tarefas e ajudando os que não fizeram em casa, uns por falta de tempo, outros porque não conseguiram. Vou ajudar os que não fizeram, sempre tem aquele que já está na terceira atividade. Simone -34 anos

- Mas e quando não temos acesso a xerox, ou mimeógrafo? Maria Heloísa -38 anos

- Não trabalho só com atividades mimeografadas, mas dou uma seqüência, deixo atividades no quadro. Simone -34 anos 
- Quando os alunos vão terminando suas atividades um vai ajudando o outro, mas mesmo assim eles ficam cobrando o olhar da professora. Foi decidido com a turma, faço sempre a avaliação com eles do que funciona, se tem alguma coisa que eu não estou conseguindo oportunizar. A turma decidiu fazer assim, e muitas vezes reúno a turma para realizar atividades com todos juntos. Mirna -40 anos

- Trabalho muito em grupo, mas sempre estabelecendo pautas de trabalho. Ao final faço a socialização das atividades. Mais ou menos de duas em duas semanas faço atividades relâmpago, eles gostam, e cobram, eles querem saber como estão, me dizem: "Ó Pedro, será que estou melhorando"? É muito importante estabelecer essa relação na sala de aula, seja no EJA ou até mesmo com crianças. Pedro - 33 anos

Materializam-se nas falas indícios de práticas organizadas diferentemente das previstas na escola dita "regular", na qual temos um conteúdo programático previsto e todos os alunos devem apreendê-lo ao mesmo tempo, como se os sujeitos tivessem os mesmos ritmos de aprendizagens.

No processo de escolarização de jovens e adultos situado pelos professores desta investigação, percebem-se nos seus dizeres modos de lidar efetiva e objetivamente com esses diferentes ritmos de aprendizagem, em termos de apropriação do conhecimento:

(...) pois tenho aqueles que têm mais dificuldade, e outros que vão avançando. Não consigo trabalhar, num movimento em que todos estão fazendo as mesmas atividades ao mesmo tempo! Tem uns que fazem mais rápido, com maior autonomia e outros que vão precisando de ajuda, de mediação. Aqueles que conseguem trabalhar sozinhos, vão avançando. Simone -34 anos

(...) quando tinha as duas fases juntas na mesma sala, eu já me organizava assim também. Eu concordo que é muito mais difícil, mas a gente consegue dividir o quadro em três partes e distribuir as atividades. Muitas vezes trabalho o mesmo texto e os exercícios é que vão sendo desenvolvidos por grau de profundidade, e vou realizando várias produções com base naquele texto. Simone -34 anos

Eu tenho diferentes níveis e como estou sozinha na escola, não tem outras 
turmas, muitas vezes dependendo das atividades agrupo os alunos em duas salas diferentes. Eu sou a professora, mas não trabalho sozinha, trabalho no grande grupo, sempre junto com os alunos. Mirna -40 anos

É o trabalho do professor como mediador, mesmo ele não estando ali eles trabalham. Simone -34 anos

O grupo de docentes situa que lidam com pessoas com mais conhecimento de que outros em determinado momento, com mais experiência no conhecimento e outras pessoas com um pouco menos. Uma das particularidades do trabalho de EJA que emerge nos dados é uma flexibilidade que se constrói em termos de organização metodológica e curricular, possibilitando lidar com os diferentes ritmos de aprendizagem e com as diferenças de apropriação do conhecimento. Destaca-se o fato da ação do professor como mediador nesses diferentes ritmos de aprendizagem, o que os leva a organizarem diferentes modos de lidar com a diversidade ao organizarem as atividades de ensino:

(...) a gente consegue dividir o quadro em três partes e distribuir as atividades. Muitas vezes trabalho o mesmo texto e os exercícios é que vão sendo desenvolvidos por grau de profundidade, e vou realizando várias produções com base naquele texto. Simone -34 anos

Tenho um grupo bem dinâmico, organizo uma rotina sistematizada com as áreas do conhecimento, mas procuro fazê-lo de forma interdisciplinar. No início das aulas, mostro para os alunos o que eu vou trabalhar. Trabalho texto, as palavras, nada solto, mas sempre com sentido e significado, vendo o que dá liga com os alunos. Trabalho muito em grupo, mas sempre estabelecendo pautas de trabalho. Ao final faço a socialização das atividades. Pedro -33 anos

(...) outros que vão precisando de ajuda, de mediação. Simone - 34 anos

Percebe-se assim que os docentes investigados indicam na organização do seu trabalho um movimento de atendimento dos sujeitos jovens e adultos, que não significa constituir um processo de individualização e 
homogeneização das práticas nesse atendimento, uma vez que os docentes indicam: "Eu sou a professora, mas não trabalho sozinha, trabalho no grande grupo, sempre junto com os alunos". Mirna - 40 anos, ou seja, "É o trabalho do professor como mediador, mesmo ele não estando ali eles trabalham". Simone - 34 anos

Outra dimensão percebida nas falas do grupo de professores remete aos tempos que os jovens e adultos acabam tendo para dedicar a seus estudos e às ausências que são obrigados a ter em função das necessidades de trabalho, de questões de sobrevivência e familiares.

O maior problema que enfrento é com uns alunos, senhores e jovens que trabalham com empreiteira. Então quando estão perto, fica fácil, mas quando vão para longe, vêm só umas duas vezes na semana, e eles mesmos trazem livros, eles pedem ajuda e dizem: "Professora, não me tira da chamada que eu preciso estudar"! Mirna -40 anos

Eles valorizam, querem vir à aula. Maria Heloísa -38 anos

Destaca-se nas falas destes profissionais a sinalização de um processo de constituição dos processos de escolarização que respeita e procura articular o processo pedagógico às particularidades dos sujeitos jovens e adultos. Essas particularidades remetem a uma necessidade de flexibilização, tanto curricular, como de organização e validação dos tempos escolares, uma vez que,

Os sistemas que pretendem garantir [os] direitos [de jovens e adultos] têm de se adaptar à concretude social em que os diversos setores vivem suas exigências, sobretudo quando se trata da infância, adolescência e juventude populares a quem não é dado o direito de escolher suas formas de vida e de sobrevivência. Na história da EJA, encontraremos uma constante: partir dessas formas de existência populares, dos limites de opressão e exclusão em que são forçados a ter de fazer suas escolhas entre estudar ou sobreviver, articular o tempo rígido de escola com o tempo imprevisível da sobrevivência. Essa sensibilidade para essa concretude das formas de sobreviver e esses limites a suas escolhas merece ser aprendida pelo sistema escolar se pretende ser mais público. Avançando 
nessas direções, o diálogo entre EJA e sistema escolar poderá ser mutuamente fecundo. Um diálogo eminentemente político, guiado por opções políticas, por garantias de direitos de sujeitos concretos. Não por direitos abstratos de sujeitos abstratos (ARROYO, 2005, p. 49).

Arroyo alerta ainda para o fato de que, muitas vezes, as análises sobre a EJA consistem em situar suas fragilidades relacionadas às suas características de ensino não-formal, tendendo a buscar valorização no seu enquadramento como ensino formal. No entanto, o que vejo é que a EJA, ao se constituir em processo de escolarização, já está inscrita em certa sistematização e organização. No entanto, é uma organização que precisa se constituir com práticas e tempos singulares, como uma escola efetivamente dos sujeitos jovens e adultos.

Os professores investigados, ao se referirem ao que significa o ensino na EJA, indicam, nessa relação - um ato de ensinar, subentendido como mediação por um lado, e como ajuda por outro - o que traz imiscuído, em termos discursivos, uma visão na qual se esforçam por pensar seus alunos em termos de sua "positividade", mas também com uma visão condescendente do aluno:

O ensino pode ajudar oferecendo oportunidades ao aluno.

É mediador para despertar o entusiasmo e interesse dos alunos. Posso ajudar meus alunos oferecendo-lhes maior tranqüilidade e dando mais atenção a ele.

Podemos ajudar os alunos dependendo da forma que conduzimos nosso trabalho, pois na maioria dos casos, o que falta é aumentar a autoestima de nossos alunos.

Considero a vontade que cada um tem em aprender e adquirir um pouco mais de conhecimento. Com paciência e amor é possível superar essa diferença com certeza.

Essa positividade e esse olhar de ajuda para com os alunos se inserem num processo de tentar romper com a visão de não-valorização que os sujeitos jovens adultos fazem de si ao se inserirem em ações de escolarização. 
Nos dados analisados capta-se, nas diferentes mediações propostas pelos docentes para lidar com o atendimento pedagógico na EJA, uma tensão permanente de relações de continuidade/descontinuidade entre as práticas tradicionalmente vinculadas ao ensino fundamental dito regular (origem da maioria dos professores, em relação à sua experiência anterior e formação inicial) e a necessidade de recriá-las, de modo a atender às necessidades dos sujeitos jovens adultos.

Essa tensão se indicia pela recriação dos modos de atendimento próprio do ensino regular, tais como a organização dos alunos de acordo com os diferentes ritmos de trabalho, a idéia da potencialidade dos sujeitos na aprendizagem, o uso de recursos lúdicos, a necessidade de se conhecer efetivamente o sujeito real de direito à educação, entre outras práticas. Esse processo evidencia a possibilidade de situarem as particularidades das práticas escolares da EJA e vem fazendo com que se revise a lógica da organização do sistema escolar "dito" regular, buscando-se "formas mais inclusivas, igualitárias de garantir esses direitos" (ARROYO, 2005, p. 43-44).

\section{A valorização do sujeito da aprendizagem: uma outra construção social na relação com o saber}

Pensar uma escola que efetivamente considere os sujeitos jovens e adultos, uma escola que saiba "ensinar considerando a valorização da individualidade sem constranger" (Neli - 35 anos) é fundamental, principalmente ao constatarmos o que afirmam os professores sobre o modo como os sujeitos jovens/adultos se identificam ao se inserirem nos processos de escolarização:

Eles têm muita insegurança neles próprios, em si. Quando eles se sentem mais seguros, parece que a aprendizagem fica mais rápida para eles, as coisas têm mais sentido, têm outras visões. Maria Heloísa - 38 anos

Alguns já vêm de um sofrimento muito grande e bloquearam suas mentes. Mirna - 40 anos

Eles querem melhorar a própria auto-estima deles. Mari - 51 anos 
Dirigir o olhar para essa questão é perceber o sujeito que procura o conhecimento na escolarização na EJA como um sujeito inscrito nas práticas da história humana, já que os "Sujeitos sócio-culturais constituem-se, pois, em suas experiências vividas no mundo da vida, pelas quais se fazem a si mesmos e à história humana. Uma história-práxis de sujeitos que são, ao mesmo tempo, sua própria história" (TEIXEIRA, 1996, p.183).

Nessa perspectiva, ao analisarmos essa imagem apontada pelos docentes, de desvalorização que os alunos de EJA fazem de si, precisamos lembrar que essa imagem é construída socialmente nas próprias relações desses sujeitos com o mundo. Construída na sua relação com o "saber" e com a valorização social desse saber. Desse modo, essa desvalorização não está no sujeito em si, mas é uma imagem que constrói na distância em que ele se percebe cotidianamente com relação às suas vivências com esse saber. Charlot $(2000$, p.17/18) evidencia que tal relação é marcada assim por uma percepção de ausência e de diferença ao lidar com dificuldade com situações que impõem o uso desse saber, construindo assim uma imagem desvalorizada de si.

Vale lembrar que enquanto o aluno desenvolve ou não ações de aprendizagens com relação a determinados conhecimentos, ele aprende também sobre suas potencialidades, suas capacidades e dificuldades de lidar com o saber e modos de enfrentar tais dificuldades.

Desse modo, ao pensarmos os sujeitos jovens-adultos na sua relação com o saber " (...) é estudar esse sujeito enquanto confrontado com a necessidade de aprender e a presença de 'saber' no mundo" (CHARLOT, 2000, p. 34).

Nessa relação com o saber, em que se constrói uma imagem desvalorizada de si, precisamos considerar que,

(...) o sujeito epistêmico é o sujeito afetivo e relacional, definido por sentimentos e emoções em situação e em ato; isto é - para não recorrer a algo inapreensível - o sujeito como sistemas de condutas relacionais, como conjunto de processos psíquicos implementados nas relações com os outros e consigo mesmo (CHARLOT, 2000, p. 70).

Também Paulo Freire (1980, p. 73), ao falar da marginalidade dos sujeitos, apontada, muitas vezes, em visões equivocadas sobre a situação do sujeito dito analfabeto, afirmava que essa visão dava-se em função do 
não reconhecimento e da ausência de análise da realidade histórica, social, cultural e econômica em que esse sujeito se encontrava inserido. Sobre essa identificação de que o sujeito estaria "à margem", "fora de", Freire interroga: se ele está à margem, quem é o autor desse movimento que o "põe de fora"? É o próprio sujeito marginalizado que decide se colocar à margem? Essa marginalidade consiste em opção do sujeito? Ora,

Se a marginalidade não é opção, o homem marginalizado tem sido excluído do sistema social e é mantido fora dele, quer dizer, é objeto de violência. $\mathrm{O}$ homem marginalizado não é "um ser fora de". É, ao contrário, um "ser no interior de", em uma estrutura social em relação de dependência para com os que chamamos falsamente de seres autônomos. (...) Na realidade, estes homens analfabetos ou não - não são marginalizados. Repetimos: não estão "fora de", são seres "para o outro". Logo, a solução de seu problema não é converterem-se em "seres no interior de", mas em homens que se libertam, porque não são homens à margem da estrutura, mas homens oprimidos no interior desta mesma estrutura que é responsável por esta mesma dependência. Não há outro caminho para a humanização - a sua própria e a dos outros -, a não ser uma autêntica transformação da estrutura desumanizante (FREIRE,1980, p. 74-75). (Grifo acrescentado)

No seu livro Pedagogia do oprimido (1987, p. 50), Freire aponta que na sua relação com o mundo os sujeitos oprimidos quase sempre não se percebem como quem "conhece", como quem tem um conhecimento, ainda que este seja no nível da pura doxa, descrendo de si mesmo, assumindo assim uma característica de autodesvalia. Os sujeitos "têm uma crença difusa, mágica, na invulnerabilidade do opressor. (...) Até o momento em que os oprimidos não tomem consciência das razões de seu estado de opressão 'aceitam' fatalisticamente a sua exploração" (FREIRE, 1987, p. 51).

Essa noção de desvalia percebida pelo sujeito é, portanto, construída na sua relação com o mundo e com o outro e, segundo Freire (1987, p. 53/ 54), para que nos processos educativos dialógicos e emancipadores possamos contribuir para a construção de uma outra auto-imagem dos sujeitos é fundamental que acima de tudo “(...) creiamos nos homens oprimidos. Que os vejamos como capazes de pensar certo também. (...) A ação política junto aos oprimidos tem de ser, no fundo, "ação cultural" para a liberdade, por isto mesmo, ação com eles". 
Dessa forma, para Freire, a sensação de dependência emocional do sujeito constitui-se fruto de uma situação objetiva de dominação em que esse se acha, e que acaba gerando também sua visão inautêntica do mundo.

Estas reflexões são extremamente relevantes, pois no cotidiano, principalmente da EJA, ouvimos constantemente alertas de que primeiro de tudo é preciso trabalhar a auto-estima dos educandos. O problema com esta expressão é que, semanticamente, auto remete a "por si próprio", "de si mesmo", já estima, indica "sentimento da importância ou do valor de alguém ou de alguma coisa; apreço, consideração, respeito" (FERREIRA, 1975 , p. 162 e 582). Logo, o termo auto-estima nos leva a pensar o valor de si mesmo, considerado por si próprio.

Ora, nesse sentido, seria legitimar a visão de que o problema da questão da distância do sujeito na sua relação com o saber estaria centrado no próprio sujeito, quando na realidade essa é efetivamente uma relação construída e inscrita nas práticas excludentes da história humana, já que,

Sujeitos sócio-culturais são também seres concretos e plurais. São pessoas vivas e reais, existindo a partir de sua corporeidade e lugar social, a partir de sua condição de mulheres, homens, negros, brancos. Pertencem a diferentes raças e etnias. São crianças, jovens ou de mais idade, adeptos de variadas crenças e costumes. Têm desejos, projetos e atribuem variadas significações às suas experiências e ao mundo. Para entendê-los, é necessário considerar esses seus atributos, sejam eles adscritos ou adquiridos, pois tudo isso matiza sua existência e condição (TEIXEIRA, 1996, p. 185).

Nesse sentido, opta-se por tomar emprestado de Charlot o termo uma imagem desvalorizada que os sujeitos têm de si no contexto das relações sociais. Imagem que é construída sócio-historicamente.

E como as professoras e professores de EJA lidam com essa questão no âmbito de sua prática docente? 


\section{Reciprocidade e acolhimento: ações intencionais no processo ensino-aprendizagem}

Em primeira instância, o trabalho docente está intimamente relacionado ao processo ensino-aprendizagem - a uma ação didática -, porém, é marcado também por outros elementos que constituem a docência.

Uma questão que se salienta nos dizeres dos professores pesquisados é o envolvimento do trabalho docente com a questão relacional, como uma dimensão primeira desse trabalho na mediação com o conhecimento, pois "professores constituem-se e identificam-se como tais a partir de suas relações com seus alunos. E estes, de igual forma” (TEIXEIRA, 1996, p. 187).

Nessas relações há um envolvimento humano, marcado por trocas, conflitos, diálogos, negociações, empenho e uma intimidade entre docentes e discentes. A própria pesquisadora Inês Castro Teixeira questiona:

E por que são também relações de intimidade? Aqui se observa o gesto e a palavra não programados, enredando o professor e aluno numa convivência impregnada de calor humano, de sentimentos e não apenas estabelecida em funções e papéis sociais. Essa intimidade transparece na espontaneidade presente em situações corriqueiras, em que as palavras e gestos estão mais soltos. Na verdade, a proximidade e convivência cotidiana faz surgir uma certa liberdade e acolhimento mútuo entre professores e alunos. Há momentos em que as teias e tons de suas relações extrapolam os conteúdos e normas escolares, escapando aos figurinos e regulamentação. Nesse sentido, sua convivência caracteriza-se também por uma certa imprevisibilidade. Nem sempre uma aula é o que dela se espera... Nem sempre é possível cumprir tudo o que estava programado... Alunos e professores podem surpreender-se uns aos outros... (TEIXEIRA, 1996, p.188). (Grifos acrescentados)

As falas dos professores investigados vêm mostrando a sala da aula de EJA como um espaço do fluir dessa intimidade em que “(...) procuro deixá-los bem à vontade e mostrar-me bem aberta para conversar sobre qualquer dúvida ou assunto". Maria Heloísa - 38 anos

Capta-se a sinalização de uma perspectiva em que ensinar e aprender estão intrinsecamente articulados com uma relação de reciprocidade, de diálogo entre os alunos e docentes, uma vez que, 
Trabalho o conhecimento, mas converso muito com ele sobre a vida, sobre o exercício. É diferente, por exemplo, tenho cinco níveis, tenho um aluno que eu já estava alfabetizando, teve toxoplasmose, perdeu grande parte da visão, preciso escrever com letra bem grande para ele enxergar, mas ele continua, é muito inteligente. Tenho uma senhora de 70 anos que está se alfabetizando agora, vou mais cedo para trabalhar com ela individualmente, quando os outros chegam já estou trabalhando com ela. Passo a mão na cabeça, há uma relação de carinho grande. Taís -42 anos

É pensar a relação com o saber inscrita numa relação com o outro e consigo mesmo, por compreender que

Toda relação consigo é também relação com o outro, e toda relação com o outro é também relação consigo próprio. Há aí um princípio essencial para a construção de uma sociologia do sujeito: é porque cada um leva em si o fantasma do outro e porque, inversamente, as relações sociais geram efeitos sobre os sujeitos que é possível uma sociologia do sujeito. Aí, também, um princípio fundamental para compreender-se a experiência escolar e para analisar-se a relação com o saber: a experiência escolar é, indissociavelmente, relação consigo, relação com os outros (professores e colegas), relação com o saber (CHARLOT, 2000, p. 47).

Essa relação dialógica constatada nas falas do grupo de professores, enquanto uma forma de lidar também com a imagem de desvalorização que os sujeitos têm de si, pelo acolhimento para o processo ensino-aprendizagem, nos aponta um fazer docente no sentido de criar um espaço de relações apropriadas para esse processo.

Marília Carvalho (1999), em seu livro No coração da sala de aula, com base nos estudos de gênero, analisa ações de atenção aos alunos no contexto do trabalho docente nas séries iniciais de crianças.

Enfim, em sua prática docente, as professoras e professores (...) usavam de muitas formas, até mesmo pelo avesso, conhecimentos, valores e estratégias aprendidos na vida familiar e doméstica e em suas experiências como mulher ou homem. E também pareciam fazer o inverso, levando para casa modelos, práticas e saberes desenvolvidos na experiência docente. 
Em suas falas, associavam em certa medida as relações com filhos e com alunos, mas não as confundiam ou identificavam plenamente e suas práticas de "cuidado" em sala de aula eram informadas ao mesmo tempo por uma cultura escolar e por características adquiridas na socialização familiar. $\mathrm{Na}$ medida em que sua identidade pessoal estava intensamente imbricada a sua ocupação e que o trabalho com as crianças envolvia fortes pressões emocionais, elas e ele atuavam na sala de aula com suas entranhas $e$ emoções, seus sonhos e suas angústias, que são inevitavelmente em nossa sociedade, entranhas, emoções, sonhos e angústias de mulher ou de homem, de pessoas marcadas [também] pelas relações de gênero (CARVALHO, 1999, p. 230). (Grifo acrescentado)

Com relação a essas práticas de cuidado ${ }^{1}$, a pesquisadora vai conceituálas como um componente fundamental na educação das crianças por parte dos professores, compreendida como uma disponibilidade emocional e uma intencionalidade que não se opõe ao ensino e à apropriação do conhecimento. Mas o que significa esse cuidado, no caso do aluno jovem e adulto?

Ribeiro (1999, p. 3, 4 e 6) vai alertar para o risco de esse cuidado vir a ser compreendido numa perspectiva elitista, de julgamento moral dos alunos e de suas famílias, ao ser visto como um aspecto específico da educação de crianças quando dirigido a compensar pretensas carências, além de poder ser entendido como uma ação assistencialista para com o educando jovem-adulto. Nesse sentido, Ribeiro ressalta esse cuidado como a importância do estabelecimento do diálogo como princípio educativo numa relação de reciprocidade entre professor e aluno.

Nesse caso, opta-se por definir as ações de cuidado das professoras e professor investigados como uma intencionalidade de acolhimento do sujeito para o ato de conhecimento.

Essa intencionalidade ao acolhimento é percebida quando as professoras e professor indicam que:

Todos são capazes de aprender, no entanto não acreditam que são capazes de aprender, então preciso ajudar mostrando alternativas para o aluno desenvolver seu potencial. Silvia -35

1 O conceito de cuidado vem sendo estudado no âmbito dos estudos da Educação Infantil, na qual o binômio educar/cuidar constitui um dos seus principais objetivos. Além disso, Kramer vem trabalhando com a noção de que o cuidado está envolvido em todos os processos educativos, tanto de crianças, jovens e adultos (KRAMER, 2003, p. 74). 
Tudo depende do mediador para despertar o entusiasmo e interesse dos alunos. Laís - 35 anos

Posso ajudar meus alunos, oferecendo-lhes maior tranqüilidade e dando mais atenção a eles. Mari - 51 anos

Posso ajudar meus alunos a superar suas dificuldades, partindo de várias atividades lúdicas. Pedro - 33 anos

É possível ajudar o adulto por meio da confiança do educando no educador. Neli -35 anos

Podemos ajudar os alunos, dependendo da forma como conduzimos nosso trabalho, pois na maioria dos casos o que falta é aumentar a auto-estima de nossos alunos. Simone -34 anos

O que diferencia a EJA é a forma que se estabelece a relação professoraluno, que envolve paciência e muita compreensão. Mirna - 40 anos

Aponta-se nessas falas um movimento de provimento de condições para o ato de conhecer, como ação de mobilização para, de diálogo no sentido da desmitificação da própria imagem de desvalorização dos alunos, na sua própria relação com o processo de aprendizagem desse saber. $\mathrm{O}$ provimento dessas condições pode viabilizar uma outra relação com o saber.

Segundo Charlot (2000, p. 54), essa relação implica atividade e para tal o sujeito precisa se mobilizar. Para que haja essa mobilização para com o ato do conhecimento, é necessário que o sujeito perceba sentidos e significados nessa atividade. "Mobilizar-se é também engajar-se em uma atividade originada por móbiles, porque existem 'boas razões' para fazê-lo" (CHARLOT, 2000, p. 55)

Nesse sentido,

(...) a intervenção educativa teria que atuar sobre os indivíduos necessariamente diversos, no sentido de lhes dar acesso àquela modalidade particular de relação entre sujeitos e objetos de conhecimento que é própria da escola, promovendo transformações específicas no seu percurso de desenvolvimento (OLIVEIRA, 1997, p. 60-61). 
Transformações que poderão possibilitar também que o sujeito se perceba como sujeito de conhecimento e, portanto, também de se sentir como capaz de pensar certo também. “(...) A ação política junto aos oprimidos tem de ser, no fundo, 'ação cultural' para a liberdade, por isto mesmo, ação com eles” (FREIRE 1987, p. 54).

\section{Algumas considerações}

No estudo constata-se uma docência na qual o sujeito se torna professor/a no seu fazer e no seu caminhar, que vem contribuindo para a construção de um estatuto próprio de EJA, para a produção e acúmulo de saberes teórico-metodológicos, potencializando um campo pedagógico e de pesquisa. Neste processo, reafirma-se a idéia da necessidade de uma formação que contemple as particularidades da EJA, seus conhecimentos e saberes teórico-metodológicos, bem como a necessidade de pensá-la como área de estudo fundamental nos cursos de formação de docentes em nível superior. Constitui-se, assim, a Educação de Jovens e Adultos não somente pela oferta da escolarização e viabilização da apropriação de saberes, mas também pelo fato de que os sujeitos jovens e adultos encontram nessa escola um espaço que lhes é de direito e no qual interagem socialmente.

\section{REFERÊNCIAS}

ARROYO, M. G. Educação de jovens - adultos: um campo de direitos e de responsabilidade pública. In: SOARES, L. (Org.). Diálogos na educação de jovens e adultos. São Paulo: Autêntica, 2005.

CARVALHO, M. P. de. No coração da sala de aula: gênero e trabalho. São Paulo: Xamã, 1999.

CHARLOT, B. Da relação com o saber. Porto Alegre: Artes Médicas, 2000.

CHARLOT, B. O sujeito e a relação com o saber. In: BARBOSA, R. L. L. (Org.). Formação de educadores: desafios e perspectivas. São Paulo: Editora UNESP, 2003.

DAYRELL, J. T. A juventude e a educação de jovens e adultos: reflexões iniciais. Novos 
sujeitos. In: SOARES, L. (Org.). Diálogos na educação de jovens e adultos. São Paulo: Autêntica, 2005.

DAYRELL, J. T. (Org.). Múltiplos olhares sobre educação e cultura. Belo Horizonte: UFMG, 1996.

DI PIERRO, M. C. R., MASAGÃO, V.; JOIA, O. Visões da educação de jovens e adultos no Brasil. Cadernos do CEDES, Campinas, n. 55, p. 58-77, 2001.

FERREIRA, A. B. de H. Novo Dicionário da Língua Portuguesa. Rio de Janeiro: Ed. Nova Fronteira, 1975.

FREIRE, Paulo. Conscientização: teoria e prática da libertação. São Paulo: Cortez e Moraes, 1980.

FREIRE, P. Pedagogia do oprimido. Rio de Janeiro: Paz e Terra, 1987.

GIOVANETTI, M. A. G. C. A formação de educadores do EJA: o legado da educação popular. In: SOARES, L. (Org.). Diálogos na educação de jovens e adultos. São Paulo: Autêntica, 2005.

KRAMER, S. Direitos da criança e projeto político pedagógico de educação infantil. In: BAZÍLIO, L. C.; KRAMER, S. Infância, Educação e Direitos Humanos. São Paulo: Cortez, 2003.

LAFFIN, M. E. L. F. Tempos e percursos de jovens e adultos: por uma escolaridade 'não perdida'. In: SEMINÁRIO DE PESQUISA EM EDUCAÇÃO DA REGIÃO SUL, 6. , Santa Maria, 2006. CD-ROM - VIANPED SUL. Santa Maria: PPGE/UFSM, 2006.

OLIVEIRA, M. K. de. Jovens e adultos como sujeitos de conhecimento e aprendizagem. In: RIBEIRO, V. M. (Org.). Educação de Jovens e adultos: novos leitores, novas leituras. 1. ed. Campinas/SP, 2001, v. 01, p. 15-43.

RIBEIRO, V. M. A formação de educadores e a constituição da educação de jovens e adultos como campo pedagógico. Educ. Soc. [online]. dez. 1999, v. 20, n. 68 [citado 03 Agosto 2005], p.184-201. Disponível na World Wide Web: <http://www.scielo.br/ scielo.php?script=sci_arttext\&pid=S0101-73301999000300010\&lng=pt\&nrm=iso $>$. ISSN 0101-7330.

RIBEIRO, V. M. (Org.). Educação de Jovens e Adultos: novos leitores, novas leituras. 1. ed. Campinas/São Paulo, 2001, v. 1, p. 15-43.

SOARES, L. (Org.). Diálogos na educação de jovens e adultos. São Paulo: Autêntica, 2005.

TEIXEIRA, I. C. Os professores como sujeitos sócio-culturais. In: DAYRELL, J. T. (Org.). Múltiplos olhares sobre educação e cultura. Belo Horizonte: UFMG, 1996.

Texto recebido em 02 de dez. 2006

Texto aprovado em 15 de fev. 2007 